\title{
The Effect of Job Orientation and Job Stress on Marital Adjustment among Guilan Office of Education Staff
}

\author{
Abbas Sadeghi ${ }^{*}$, Zahra Khedmati ${ }^{2}$, Aram Yousefi ${ }^{2}$ \\ ${ }^{1}$ Department of Educational Sciences, University of Guilan, Rasht, Iran \\ ${ }^{2}$ Department of General Psychology, University of Islamic Azad University, Rasht, Iran \\ Email: *asadeghi1394@gmail.com
}

How to cite this paper: Sadeghi, A., Khedmati, Z., \& Yousefi, A. (2018). The Effect of Job Orientation and Job Stress on Marital Adjustment among Guilan Office of Education Staff. Sociology Mind, 8, 83-94. https://doi.org/10.4236/sm.2018.82006

Received: January 20, 2018

Accepted: March 2, 2018

Published: March 5, 2018

Copyright $\odot 2018$ by authors and Scientific Research Publishing Inc. This work is licensed under the Creative Commons Attribution International License (CC BY 4.0).

http://creativecommons.org/licenses/by/4.0/

\section{(c) (i) Open Access}

\begin{abstract}
Family is a social unit, an organization, a group and also a small society that, in sociologists' view, is the first structured unit in a social system. A healthy society requires a healthy family and marital adjustment is one of its requirements. On this basis, this study aimed to identify the effect of job orientation and job stress on marital adjustment among Guilan Office of Education staff. Statistical population of this study was Guilan Office of Education staff in 2015 that 100 people were selected with random sampling method. Results: this study showed that there is a significant relationship between life orientation and job stress with marital adjustment. Also, life orientation and job stress could predict $21 \%$ of variances in marital adjustment. Conclusion: according to these findings it can be said that higher optimism in life and less job stress lead to higher marital adjustment among couples.
\end{abstract}

\section{Keywords}

Marital Adjustment, Life Orientation, Job Stress

\section{Introduction}

Human beings continually are faced with various roles environmental demands and pressures such that they have to adjust themselves with them throughout their life. People always strive for well-being and happiness in different aspects of their personal, social, economic, marital and work life (Koshy, 2013).

Family is one of the most important principal institutions in any society. Achieving to healthy society is obviously associated with a healthy family which itself is actualized through mental health and good relationship of family mem- 
bers (Assad, Donnellan, \& Conger, 2007). Marriage is considered as a formal and important event in almost any society (Ford, Heinen, \& Longkamer, 2007). Marriage and marital relationship are sources of support, friendship and pleasure. Furthermore, it causes cooperation, sympathy, kindness, patience and responsibility towards family (Bohm, Schutz, Rentzsch, Korner, \& Funke, 2010). There are several factors effective on endurance of marital life and the main factor is maybe adjustment towards stressful stimulants. The ability of adjustment with different situations in a fast-changing and progressive society is not an easy task. Epidemiologic surveys show that lack of marital adjustment is a risk factor for diseases and mortality. Also, couples' mental and physical health is affected by aggressive relationship (Deshpande \& Sarda, 2014). Marital adjustment is defined as coordination and sympathy in achieving common goals in husband and wife's life which leads to mutual satisfaction. Adjustment between husband and wife makes it possible for them to avoid from conflicts or to solve them wisely such that both sides feel satisfied from each other (Driver \& Gottman, 2004).

Also, marital adjustment is considered as one of the most important effective factors on marital life's endurance and stability. Lavner et al. (2013) showed that more pleasant marital status is associated with better mental health and personal well-being and low marital adjustment is particularly associated with higher risks of depression and other psychological disorders.

Marital adjustment is referred to the state of overall happiness and satisfaction feeling in husband and wife with regards to their marriage and with each other (Koshy, 2013; Singha, 2016). Work and family have always been two important issues in our lives and a balanced work-family surely will lead to more individual and social well-being (Stoner et al., 1998). Marriage is perceived as a social security for all the individuals as marriage system provides security of needs and cares for individuals in the society. Marital adjustment is an evolutional process between couples that gradually is created during marital life. Marital adjustment influences on several aspects of individual and social life such as personality, job stresses, mental health, depression, education, sexual satisfaction, attitude, happiness and success in life (Hashmi et al., 2007; Koshy, 2013; Sinha, 2016). The present study is an attempt to investigate marital adjustment among working women.

Job stress refers to any negative experience that is caused by an imbalance between job demands and job-related difficulties (Parveen, 2009). Also, it is the way people may response to work demands and pressures that are beyond their knowledge and capabilities. It has several causes such as workload, long work hours, insufficient organizational, supervisor and colleagues support, work-family, job demands and pressures (Stoner et al., 1998; Mukosolu et al., 2015). McGowan et al. (2006) refers it as a state of the organism resulting from some interaction with the environment. Mukosolu et al. (2015) defined it as an interaction between the person and the environment that is appraised by the person as taxing or exceeding his or her resources and is associated with his or her well-being. As working women generally have more dominant role in the family, as well as 
in the workplace so they experience high level of stress due to over workload or pressure (Koshy, 2013).

Research studies suggest that women often experience more problems with regards to work-family conflict and family and word demands and pressures (Koshy, 2013; Parveen, 2009; Sinha, 2016; Sahu \& Singh, 2014). For example, in their study about depression of working women and housewives and its relationship with social support and marital adjustment, Mohammadi et al. (2011) found that working women experience less depression than housekeeping women. However, Sahu \& Singh (2014) investigated mental health and marital adjustment of working and non-working married women and found no significant differences in mental health as well as in marital adjustment of working and non-working married women with regards to dimensions of mental health.

However, Vaghela (2014) and PishGhadam et al. (2013) conducted a comparative study about marital adjustment among employed and unemployed married women of urban and rural area. Contrarily, their main findings showed a significant difference between marital adjustment scores of employed and unemployed married women of urban area. Therefore, they concluded that employed women are generally more satisfied with their lives and marriage than non-employed women. It seems that there is difference between these findings that could be attributed to cultural differences (PishGhadam et al., 2013).

Job related stresses are one of effective factors on marital adjustment. On the other side, stress is considered as one of the most general problems is couples' daily life. It is so commonplace and prevalence that sometimes is considered as a characteristic of marital life such that all families are faced with a lot of stresses in daily life which considerably affect them (Byrns, Agnew, \& Curbow, 2002). Job stress can be defined as experiencing stressful situations in workplace that most people experience them in their career. Also, it is defined as interactions between work condition and worker's personal trait such that workplaces' expectations are beyond individuals' abilities Mohammadi et al. (2011). Selye (1950) defines stress as a spontaneous reaction to situations which need energy mobilization. In this regard, factor like work environment, assigned responsibilities, possible problems and job duties are very stressful. Job stress can be defined as experiencing stressful situations in workplace that most people experience them in their career (Haj Bagheri, Lotfi, \& Sadat Hoseini, 2014). In fact, it can be considered as a biological, psychological and cognitive process that makes our body active and the body naturally tries to conform to this situation. This is accompanied with energy consumption, fighting against diseases and vital responses (Aghilinejad, Mohammadi, Afkari, \& Abbaszadeh, 2007).

From Norito et al. (1999)'s view, job stress is considered as the most powerful psychological problem-making factors. They believe that it has various effects on personal and occupational life (Obradović \& Čudina, 2011). On the other words, mental health, quality of life, family life and life satisfaction are among the most important consequences of job stress (Bolger, DeLongis, Kessler, \& Wethington, 1989; Obradović \& Čudina, 2011). In fact, workers that experience working 
beyond their capabilities, household responsibilities, unbalanced work-family role duties and family/marriage roles are included in vulnerable groups (Paden \& Buehler, 1995; cited by Obradović \& Čudina, 2011). In this respect, Roberts \& Levenson (2001) believe that physical fatigue, as a strain resource, can lead to anxiety, stress and incorrect behaviors in family.

Also, studies have shown that job stress has profound effect on family unit and subsequently marital adjustment. For example, Steenbergen, Kluwer, \& Karney (2011) reported in their study that job stress can have negative effects on all aspects of individual life.

In this respect, $\mathrm{Li}$ et al. (2016) investigated the effect of work stress in Chinese working women. They suggested that the relationship between work stress and cardiopulmonary, gastrointestinal complaints, general pain, fatigue and other similar somatic symptoms was particularly pronounced in women such that about $52 \%$ of participants reported high work stress. They concluded that work stress is strongly associated with somatic symptoms in Chinese working women.

Life orientation is one of other effective factors on marital adjustment. People with positive life orientation (optimism) experience daily events positively and expect more positive results compared to pessimists (Scheier \& Carver, 1987, 1992). In fact, positive life orientation has a significant effect on individual life such that more optimist people attract higher social support; use adaptive coping guidelines and have different hygienic habits compared to optimists that always give up against stressful situations and change their path (Brissette, Scheier, \& Carver, 2002; Scheier \& Carver, 1987, 1992). Studies have shown that optimism and not having pessimistic orientation towards life help affective adjustment, mental health and well-being to be increased (Boehm \& Kubzansky, 2012; Rasmussen, Scheier, \& Greenhouse, 2009). Evidences indicate that low-developmental positive orientation towards life is associated with stress and depression symptoms after life experienced strains (Brissette et al., 2002).

Studies have shown that optimism in the elderly is associated with highest general health, well-being and perceived mental health and is accompanied with lowest level of physical pain (Achat, Kawachi, Spiro, DeMolles, \& Sparrow, 2000). Researchers generally believe that positive life orientation (optimism) helped to reinforcement and endurance of social relationships (Carver et al., 2010; Assad et al., 2007; Machaty, 2013). For example, optimist people with positive attitudes towards life are more successful in marital relationship and less think about ending up their relationship (Eastwick, Finkel, Krishnamurti, \& Loewenstein, 2008; Lavner, Karney, \& Bradbury, 2013). On the other side, pessimist people less make use of effective stress coping strategies in their life and have less conflict-solving abilities compared to optimists which in turn will increase their marital adjustment (Deshpande \& Sarda, 2014; Srivastava, McGonigal, \& Richards, 2006). For example, Srivastava et al. (2006) showed that when couples have optimistic attitudes towards life, they have higher levels of life satisfaction compared to more pessimist couples. 
Generally, individuals have different orientations to work at different stages of life. Arthur (1987) maintains that job satisfaction depends in part on the expectations people bring with them to the job. Individual orientations included psychological orientation, job orientation, and personal attributes. The work situation was composed of job characteristics and job environment (Arthur, 1987). Research results show that life orientation and life satisfaction are significant predictors of psychological well-being. Therefore, prevailing working environment will enhance positive orientation towards life and in turn enhance life satisfaction, increase quality of life and improve interpersonal relationship (Rathore et al., 2015; Aghaei et al., 2013).

According to these subjects, the aim of this study is to answer this question that is there any relationship between life orientation and job stress and marital adjustment?

\section{Methodology}

This study was conducted in 2015-16 among Guilan Office of Education staff. A sample of 100 workers (50 men and 50 women) was surveyed through random sampling method.

\section{Research Instruments}

Job Stress Questionnaire (HSE): Job Stress Questionnaire (HSE) is provided by Britain Health and Safety Executive. It consists of 35 questions with a 5-item Likert scale. In this questionnaire, 8 questions are related to demands, 6 about control, 3 about change, 4 about relationship, 5 about roles, and 9 about support.

Locke and Wallace marital adjustment test (LWMAT): this test consists of 15 questions and it is one of the first brief measures of marital adjustment. Each question has different score value. It can differentiate between well-adjusted couples and distressed couples and has high reliability.

Life Orientation Test (LOT): this questionnaire was constructed by Scheier \& Carver (1987) for measuring dispositional optimism. It consists of 8 coded items. Half the items are framed in an optimistic manner; half in a pessimistic manner and respondent indicate their extent of agreement or disagreement with each item on a multi-point scale. It has good psychometric properties, in most respects. However, it was criticized because the optimistic and pessimistic item sets form two factors that not always highly inter-related. Following studies such as Scheier \& Carver (1987) and Scheier \& Carver (1992) have shown that dispositional optimism and pessimism are related to wide range of related constructs such as self-esteem, hopelessness and psychoneurotic distress which indicates convergent validity of this questionnaire.

\section{Findings and Discussion}

According to our results, mean age of participants was 38.93 (standard deviation $=8.67$ ) and most of them have a M.Sc. degree. As can be seen in Table 1, there is 
Table 1. Pearson correlation coefficients between research variables.

\begin{tabular}{cccc}
\hline variable & SE & 1 & 2 \\
\hline life orientation & $16.34(4.92)$ & 1 & 1 \\
job stress & $129.3(16.4)$ & $-0.43^{* *}$ & $-0.40^{* *}$ \\
marital adjustment & $18.76(5.93)$ & $0.37^{* *}$ & \\
\hline
\end{tabular}

a negative significant correlation between job stress and marital adjustment and a positive significant correlation between life orientation and marital adjustment.

A stepwise statistical regression was used for determining the role of life orientation and job stress in predicting marital adjustment. For this purpose, life orientation and job stress were separately added to regression equation as predictive variables. The results of regression analyses are presented in Table 2.

The results show that $\mathrm{F}$ is significant $(P<0.01)$ and $21 \%$ of marital adjustment variances can be explained by life orientation and job stress. Regression coefficients show that job stress $(\beta=-0.175)$ and life orientation $(\beta=-0.137)$ can significantly explain marital adjustment variances. As can be seen in Table 1 , there is a negative significant correlation between job stress and marital adjustment and a positive significant correlation between life orientation and marital adjustment.

Our results showed that there is a negative significant correlation between job stress and marital adjustment and a positive significant correlation between life orientation and marital adjustment. On the other words, higher positive life orientation leads to more marital adjustment. In another aspect, when job stress is high, marital adjustment is lower. This finding is consistent with Steenbergen et al. (2011), Koshy (2013), Hashmi et al. (2007), Sinha (2016), Parveen (2009), Vaghela (2014)'s results while it was inconsistent with the results of Sahu \& Singh (2014) who found no significant relationship between job stress and marital adjustment. The reason is that employed married women have often better positive relationship with others and so they can better create a healthy and happy atmosphere for their marital adjustment (Vaghela, 2014; PishGhadam et al., 2013; Sahu \& Singh, 2014; Mohammadi et al., 2011).

Marital satisfaction is one of effective factors on family stability and endurance and mental health of couples, children and society. There are several factorsthat cause couples to feel satisfied from each other. Marital adjustment is effective in individual and social aspects of life in many respects. In fact, it is the base of good family performance; facilitates parent's roles; increases couples' lifetime; increases health and economic development; leads to more satisfaction from life; decreases psychological problems; better management of conflicts; better communication skills; and higher problem-solving abilities (Hosseininasab et al., 2009). 
Table 2. A summary of regression model, valiance and statistical characteristics of life orientation and job stress regressions.

\begin{tabular}{cccccccc}
\hline model/marital adjustment & $\mathrm{t}^{*}$ & $\mathrm{~B}$ & $\beta$ & $\mathrm{SE}$ & $\mathrm{R}^{2}$ & $\mathrm{R}$ & $\mathrm{F}$ \\
\hline job stress & 18.08 & 0.40 & 0.16 & -0.213 & -0.175 & 1.32 & \\
life orientation & 14.52 & 0.46 & 0.21 & 0.168 & 0.137 & 0.95 \\
\hline
\end{tabular}

In Koshy's study on working women, the majority of respondents with receive high salary reported marital adjustment problems and these problems were more profound in married women with more than 10 years of work experience. Marriage is considered as a significant event effective on individual's quality of life and this is especially true for women in developing countries where traditional concept of family and gender roles is more intense. Koshy (2013) concluded that marital adjustment among the working women will lead to joint family and he argued that this is because working women have to take multiple roles and responsibilities in their marital life such as taking care of children, husband and finally work. Although few respondents reported occupational stress due to the multiple roles they have to take, with regard to the marital adjustment, majority of them expressed lower levels of sexual, social and emotional adjustment. Moreover, he found that emotional adjustment was positively correlated with the sexual adjustment and social adjustment.

Similarly, Vaghela (2014), PishGhadam et al. (2013), Sahu \& Singh (2014) and Mohammadi et al. (2011) have discussed about the stress faced by married women in working place and found similar results that was consistent with this study's findings too. In fact, researches have shown that strenuous working conditions, role overload, work-family conflict, personal life-related stress and role ambiguity leads to negative outcome and reduce self-confidence, sense of hopelessness, anxiety and depression amongst employees regardless of gender and they are all significant contributors in work stress (Arthur, 1987; Coetzee \& de Villiers, 2010; Mukherjee, 2012; Mukosolu et al., 2015). However, results of the present study are in accordance with the results obtained by Koshy (2013), Vaghela (2014), PishGhadam et al. (2013), Sahu \& Singh (2014), Parveen (2009) and Mohammadi et al. (2011) in which it was found that women suffer more from workplace-related stresses. For example, Parveen (2009) argues that higher levels of occupational stress reported by married women are explained by traditional trends, society demands and assigned roles and responsibilities for them as a wife or a mother.

Lack of adjustment eliminates these positive aspects and raises many individual and social problems. On this basis, this study investigated the effects of life orientation and job stress on marital adjustment.

In this respect, regression results indicated that life orientation is one of the effective factors on marital adjustment such that couples' life orientation (optimism and pessimism), positive attitude, sense of humor, affection, and positive notions have important roles in stimulating marital association and improving 
marital relationships (Machaty, 2013; Gordon \& Baucom, 2009). As this study showed too, respondents' marital adjustment can be predicted by their orientations about life. This finding is consistent with Eastwick et al. (2008), Lavner et al. (2013) and Deshpande \& Sarda (2014), Rathore et al. (2015), Mukherjee (2012), Coetzee \& de Villiers (2010), White \& Ma (2014) and Hashmi et al. (2007).

In this respect, Rathore et al. (2015) investigated predictability of psychological well-being with regards to life satisfaction and life orientation. Their results showed that life orientation and life satisfaction was the significant predictors of psychological well-being. Therefore, they concluded good working environment can enhance positive orientation towards one's life which in turn will increase life satisfaction. They also argued that accurate determination of the extent of psychological well-being is a key positive force for life satisfaction and life orientation. That is, having positive feelings and positive mental attitudes can improve people's quality of life and decrease their stresses. On the other hand, people need to develop a positive attitude towards their life in order to maintain life satisfaction which in turn enhances psychological well-being.

Likewise, Mukherjee (2012) states that when mental and physical healthiness are accompanied with optimum level of occupational stress will give employees full worth to the work. He refers two distinct patterns of life orientations proposed by Bray, Campbell, \& Grant in 1974: the first one is associated with career/job success which is known as enlarging style and the other one which is associated with less success and is called enfolding style. Mukherjee (2012) further studied life-orientation, gender and occupational stress of working men and women to explore their impact on their work involvement. His results showed that life-orientation and gender have significant effects on job-involvement, while life-orientation, gender and occupational stress were not significant.

He argued that gender of the employee has an important role in workplace stresses in the context of physically strenuous working conditions such as industrial sector (Mukherjee, 2012). The reason is that a female has to cope with unfriendly physical working condition in addition to her family and marital responsibilities as both a wife and a mother. As a result, balancing work-life when family responsibility causes work stress will be very difficult. Such circumstances will lead to gradual fatigue, depression and anxiety which in turn will lead to negative attitudes towards life and pessimism (negative life orientation) (Mukherjee, 2012; Arthur, 1987; Hashmi et al., 2007).

White \& Ma (2014) examined the relationships between activity choices, perceived health, stress, and life orientation (optimism-pessimism) in a general population of healthy adults. They compared the participants' perceptions of overall health, stress levels, and degrees of optimism and pessimism (life orientation). Their findings confirmed that, generally, being engaged in more activities is associated with more perceived health, positive life orientation, and lower stress. They similarly confirmed that women tend to have higher perceived stress 
than men. They concluded that the amount and type of activity seems to be effective in terms of their overall health, stress perception, and life orientation.

In addition, Coetzee \& de Villiers (2010) propose workload as a source of job stress and report that females generally experience more negative feelings (pessimism) in their work and family life when they are faced high job pressure, work overload, time demands, little or no autonomy and little or no family and social support which in turn will lead to more stress, anxiety and depression and subsequently less marital adjustment. They argued that the reasons are lack of time, decreasing social network, losing support of friends and family members. In fact, higher job-related stresses will lead to more problems in social life and particularly in marital life. Regardless gender, job related-stresses cause less mental health, higher personal anxiety and stress and finally distressed marital relationship.

\section{Conclusion}

This study aimed to identify the effect of job orientation and job stress on marital adjustment among Guilan Office of Education staff. As our results showed too, there is a negative significant correlation between job stress and marital adjustment and a positive significant correlation between life orientation and marital adjustment. Also, we found a positive significant correlation between marital adjustment and life orientation.

Although individuals today have access to a wider range of life options, yet, for many employees, more assigned family and workplace roles will result in more stress problems in their marital life. Employees are more prone to marital adjustment problems because of work-related stresses. Multiple work and family roles will lead to sever stressful situations that put employees into an unhappy situation increases stress and will cause negative life orientation (pessimism) which in turn will lead to less marital adjustment (Koshy (2013), Vaghela (2014), PishGhadam et al. (2013), Sahu \& Sing (2014), Hashmi et al., (2007)).

\section{References}

Achat, H., Kawachi, I., Spiro, A., DeMolles, D. A., \& Sparrow, D. (2000). Optimism and Depression as Predictors of Physical and Mentalhealth Functioning: The Normative Aging Study. Annals of Behavioral Medicine, 22, 127-130. https://doi.org/10.1007/BF02895776

Adib Haj Bagheri, H., Lotfi, M. S., \& Sadat Hosseini, F. (2014). The Relationship between Job Stress and Marital Satisfaction among Nurses. Journal of Healthcare, 16, 9-18.

Aghaei, A., Khayyamnekouei, Z., \& Yousefy, A. (2013). General Health Prediction Based on Life Orientation, Quality of Life, Life Satisfaction and Age. Procedia-Social and Behavioral Sciences, 84, 569-573. https://doi.org/10.1016/j.sbspro.2013.06.605

Aghilinejad, M., Mohammadi, S., Afkari, M. E., \& Abbaszadeh Dizji, R. (2007). Surveying the Association between Occupational Stress and Mental Health, Personality and Life Stressful Events in Tehran Police Officers. Research in Medicine, 31, 355-360. 
Arthur, V. C. (1987). Job Satisfaction and Its Relationship to Gender, Career Orientation, and Childcare Needs among White Collar and Blue Collar Residence Hall Employees. Paper 8611. Retrospective Theses and Dissertations, City of Tehran: University of Tehran.

Assad, K. K., Donnellan, M. B., \& Conger, R. D. (2007). Optimism: An Enduring Resource for Romantic Relationships. Journal of Personality and Social Psychology, 93, 285-297. https://doi.org/10.1037/0022-3514.93.2.285

Boehm, J. K., \& Kubzansky, L. D. (2012). The Heart's Content: The Association between Positive Psychological Well-Being and Cardiovascular Health. Psychological Bulletin, 138, 655-691. https://doi.org/10.1037/a0027448

Bohm, R., Schutz, A., Rentzsch, K., Korner, A., \& Funke, F. (2010). Are We Looking for Positivity or Similarity in a Partner's Outlook on Life? Similarity Predicts Perceptions of Social Attractiveness and Relationship Quality. Journal of Positive Psychology, 5, 431-438. https://doi.org/10.1080/17439760.2010.534105

Bolger, N., DeLongis, A., Kessler, R., \& Wethington, E. (1989). The Contagion of Stress across Multiple Roles. Journal of Marriage and Family, 51, 175-183.

https://doi.org/10.2307/352378

Brissette, I., Scheier, M. F., \& Carver, C. S. (2002). The Role of Optimism in Social Network Development, Coping, and Psychological Adjustment during a Life Transition. Journal of Personality and Social Psychology, 82, 102-111. https://doi.org/10.1037/0022-3514.82.1.102

Byrns, G., Agnew, J., \& Curbow, B. (2002). Attributions, Stress, and Work-Related Low Back Pain. Applied Occupational and Environmental Hygiene, 17, 752-764. https://doi.org/10.1080/10473220290096050

Carver, C. S., Scheier, M. F., \& Segerstrom, S. C. (2010). Optimism. Clinical Psychology Review, 30, 879-889. https://doi.org/10.1016/j.cpr.2010.01.006

Coetzee, M., \& de Villiers, M. (2010). Sources of Job Stress, Work Engagement and Career Orientations of Employees in a South African Financial Institution. Southern African Business Review, 14, 27-58.

Deshpande, A., \& Sarda, G. (2014). Predicting Relationship Satisfaction from Dispositional Optimism amongst Young Adults in Mumbai City. Indian Journal of Mental Health, 1, 56-63.

Driver, J. L., \& Gottman, J. M. (2004). Daily Marital Interactions and Positive Affect during Marital Conflict among Newlywed Couples. Family Process, 43, 301-314. https://doi.org/10.1111/j.1545-5300.2004.00024.x

Eastwick, P. W., Finkel, E. J., Krishnamurti, T., \& Loewenstein, G. (2008). Mispredicting Distress following Romantic Breakup: Revealing the Time Course of the Affective Forecasting Error. Journal of Experimental Social Psychology, 44, 800-807. https://doi.org/10.1016/j.jesp.2007.07.001

Ford, M. T., Heinen, B. A., \& Longkamer, K. L. (2007). Work and Family Satisfaction and Conflict: A Meta-Analysis of Cross-Domain Relations. Journal of Applied Psychology, 92, 57-80. https://doi.org/10.1037/0021-9010.92.1.57

Gordon, C. L., \& Baucom, D. H. (2009). Examining the Individual within Marriage: Personal Strengths and Relationship Satisfaction. Personal Relationships, 16, 421-435. https://doi.org/10.1111/j.1475-6811.2009.01231.x

Hashmi, H. A., Khurshid, M., \& Hassan, I. (2007). Marital Adjustment, Stress and Depression among Working and Non-Working Married Women. Internet Journal of Medical Update, 2, 19-26. 
Hosseininasab, S. D., \& Nosratabad Hashemi, T. (2009). Investigation the Relationship between Religious Orientation and Marital Satisfaction. Journal of Psychology, 4, 18-24.

Koshy, S. M. (2013). Marital Adjustment and Occupational Stress of Women in Industry. International Journal of Scientific Research, 2, 578-580.

Lavner, J., Karney, B., \& Bradbury, T. (2013). Newlyweds' Optimistic Forecasts of Their Marriage: For Better or for Worse? Journal of Family Psychology, 27, 531-540. https://doi.org/10.1037/a0033423

Li, J. et al. (2016). The Association of Work Stress with Somatic Symptoms in Chinese Working Women: A Large Cross-Sectional Survey. Journal of Psychosomatic Research, $89,7-10$

Machaty, A. (2013). Dispositional Optimism and Marital Adjustment (Paper 7). Theses and Dissertations, Family Sciences. http://uknowledge.uky.edu/hes_etds/7

McGowan, J., Gardner, D., \& Fletcher, R. (2006). Positive and Negative Affective Outcomes of Occupational Stress. New Zealand Journal of Psychology, 35, 92-98.

Mohammadi, A, AdalatzadehAghdam, G., \& Ranji, S. (2011). Comparison of Postpartum Depression of Working Women and Housewives and Its Relationship with Social Support and Marital Adjustment. Procedia-Social and Behavioral Sciences, 30, 1837-1839. https://doi.org/10.1016/j.sbspro.2011.10.354

Mukherjee, D. (2012). Facilitating Productive Work Life with Respect to Life-Orientation, Gender and Occupational Stress. Journal of Organisation \& Human Behaviour, 1, 13-17.

Mukosolu, O., Ibrahim, F., Rampal, L., \& Ibrahim, N. (2015). Prevalence of Job Stress and Its Associated Factors among Universiti Putra Malaysia Staff. Malaysian Journal of Medicine and Health Sciences, 11, 27-38.

Norito, K., \& Takashi, H. (1999). Epidemiology of Job Stress and Health in Japan; Review of Current Evidence and Future Direction. Industrial Health, 37, 174-186. https://doi.org/10.2486/indhealth.37.174

Obradović, J., \& Čudina-Obradović, M. (2011). Work Stress and Marital Quality in Dual Earner. Društvenaistraživanja, 22, 673-691.

Paden, S. L., \& Buehler, C. (1995). Coping with the Dual-Income Lifestyle. Journal of Marriage and Family, 57, 101-110. https://doi.org/10.2307/353819

Parveen, N. (2009). Investigating Occupational Stress among Married and Unmarried Working Women in Hyderabad City. Bahria Journal of Psychology, 5, 31-37.

PishGhadam, M., Bakhshipour B. A., \& Ebrahimi, S. (2013). Marital Adjustment among Employed and Non-Employed Women of Tehran City. Journal of Novel Applied Sciences, 2, 784-786.

Rasmussen, H. N., Scheier, M. F., \& Greenhouse, J. B. (2009). Optimism and Physical Health: A Meta-Analytic Review. Annals of Behavioral Medicine, 37, 239-256. https://doi.org/10.1007/s12160-009-9111-x

Rathore, S., Kumar, A., \& Gautam, A. (2015). Life Satisfaction and Life Orientation as Predictors of Psychological Well Being. The International Journal of Indian Psychology, 3, 20-27.

Roberts, N. A., \& Levenson, R. W. (2001). The Remains of the Workday: Impact of Job Stress and Exhaustion on Marital Interaction in Police Couples. Journal of Marriage and Family, 63, 1052-1067. https://doi.org/10.1111/j.1741-3737.2001.01052.x

Sahu, K., \& Singh, D. (2014). Mental Health and Marital Adjustment of Working and Non-Working Married Women. International Journal of Advancement in Education 
and Social Sciences, 2, 24-28.

Scheier, M. F., \& Carver, C. S. (1987). Dispositional Optimism and Physical Well-Being: The Influence of Generalized Outcome Expectancies on Health. Journal of Personality, 55, 169-210. https://doi.org/10.1111/j.1467-6494.1987.tb00434.x

Scheier, M. F., \& Carver, C. S. (1992). Effects of Optimism on Psychological and Physical Well-Being: The Influence of Generalized Outcome Expectancies. Health Psychology, 16, 201-228.

Selye, H. (1950). The Physiology and Pathology of Exposure to Stress. Psychosomatic Research, 89, 7-10.

Sinha, Ch. (2016). Adjustment of Married Women in Relation to Age and Job Status. International Journal of Scientific and Research Publications, 6, 42-45.

Srivastava, S., McGonigal, K. M., \& Richards, J. (2006). Optimism in Close Relationships: How Seeing Things in a Positive Light Makes Themso. Journal of Personality and Social Psychology, 91, 143-153. https://doi.org/10.1037/0022-3514.91.1.143

Steenbergen, E. F., Kluwer, E., \& Karney, B. (2011). Workload and the Trajectory of Marital Satisfaction in Newlyweds: Job Satisfaction, Gender and Parental Status as Moderators. Journal of Family Psychology, 25, 345-355. https://doi.org/10.1037/a0023653

Stoner, Ch. R., Hartman, R. I., \& Arora, R. (1998). Work/Family Conflict: A Study of Women in Management. The Journal of Applied Business, 7, 67-74.

Vaghela, K. J. (2014). A Comparative Study of Marital Adjustment among Employed and Unemployed Married Women of Urban and Rural Area. The International Journal of Indian Psychology, 2, 35-40.

White, B. P., \& Ma, A. (2014). Relationships among Occupation/Activity Patterns, Health and Stress Perceptions, and Life Orientation in Well Adults. The Open Journal of Occupational Therapy, 2, Article 5. 